\title{
Design and Implementation of a Reservation System and a New Queuing for Remote Labs
}

\author{
https://doi.org/10.3991/ijoe.v15i12.11098 \\ Yassine Khazri $(\bowtie)$ \\ Hassan II University, Casablanca, Morocco \\ khazri10@gmail.com \\ Ahmed Fahli \\ Hassan I University, Settat, Morocco \\ Mohammed Moussetad \\ Hassan II University, Casablanca, Morocco \\ Ahmed Naddami \\ Hassan I University, Settat, Morocco
}

\begin{abstract}
Remote laboratories are important in education because they provide access to equipment that some institutions cannot afford to purchase or maintain, reduce the need for dedicated physical space for equipment and personnel to staff laboratories. But more than just fill the absence of real physical laboratories; remote laboratories can improve the users experience through the use of adaptive and specific. An important element in supporting shared access is coordinating the scheduling of the laboratory usage. Optimized scheduling can significantly decrease access waiting times and improve the utilization level of remote laboratories resources, with associated reductions in per-use costs.

The user management systems that exist so far are limited, and not compatible with all remote lab interface development software. For that, we worked on the development of a new user management system for remote laboratories.

This paper proposes a model and set of diagrams that define the new reservation system and a new Queuing for remote laboratories for educational purposes.
\end{abstract}

Keywords—Remote labs, queuing, reservation, ELAB FSBM, internet, UML

\section{Introduction}

The fast development of the Internet technology and its increase of popularity has an enormous impact on the process of teaching [1]. This technology offers new tools for all disciplines. These tools facilitate the strategies of education. Internet technologies associated with increasingly interactive applications and mobile and accessible interfaces can foster innovative use in the field of practical scientific and technical training [2-3-4]. At present e-learning has become important in the practical education [5]. Alternatives to face-to-face training such as remote labs may be a contribution to solving 
the problem of student massification. These distributed systems allow the sharing of material and human resources by putting online practical works accessible in real time [6-7-8]. These laboratories are computing environments and / or materials complementary to conventional training. They allow students to manipulate real devices (measurement or analysis instruments, real or robotic mechanisms, etc.)[9]. The development of such facilities allows hands-on learning for a growing number of students, despite the limited material and coaching resources [10]. They can also allow for the sharing of heavy and expensive tools and equipment across multiple institutions nationally or internationally and they protect students from dangerous manipulations. This new opportunity to perform real remote laboratory experiments allows more flexible learning and also extends the didactic means of presentation [11].

It has been identified as a major enabler in both education and research across the range of science and engineering disciplines [12-13-14]. The recent emergence of remote laboratories provides an additional approach to supporting this access. Remote laboratories provide remote access, typically across the internet, to a physical laboratory that has been appropriately instrumented so that the equipment can be controlled and monitored by the user [15-19].

This work relates to the modeling, design and implementation of an 'ELAB FSBM' platform as well as the installation of a queue for user management.

\section{Modeling and Conception of the Platform}

For the conception of our application we directed our choice to UML, who is a way to express models object by disregarding their implementation, that is the model supplied by UML is valid for any programming language.

UML tools can be used to generate code in different languages from diagram descriptions. UML has a direct relationship with object-oriented analysis and design and has become an OMG standard [16]. UML includes a graphical notation that can be used to create an abstract model of a system.

[17] UML's overall goal is to make the system easy to understand and use for users and developers [16].

The conception of the platform was schematized according, before being modeled, according to several diagrams: diagram of case of use, diagram of class, diagram of sequence etc., before being modeled.

\subsection{Diagram of case of use}

The conception requires passing through the use case to define the need for users of a computer system towards this system [18]. 


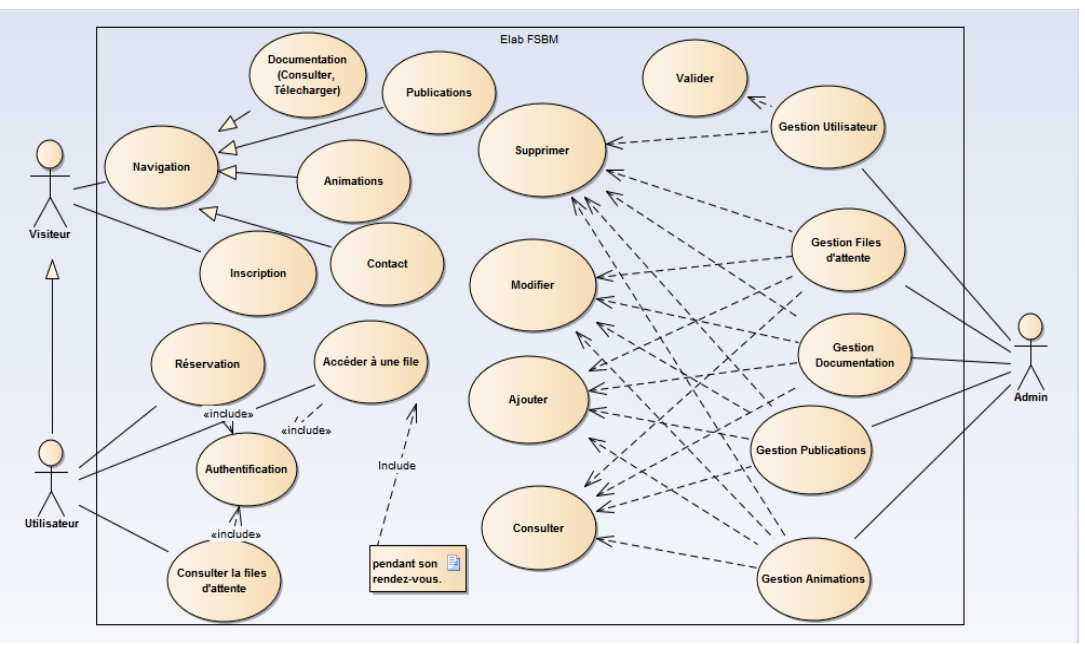

Fig. 1. Use case diagram

Our use case diagram is shown in Figure 1, it is based on three main actors, visitors, users and the administrator. Each actor will have specific spots:

The spots of a visitor: Our platform allows the visitor to make the registration on the navigation with the possibility of downloading all the proposed documents, without any authorization to enter the laboratory.

Spots of a user: The user is a visitor who made the registration in the platform, after this registration the user will be able to reserve a representation to manipulate the available practical class.

Spots of an administrator: He's the actor who manages the data of the platform altogether.

Table 1. Description of the elements

\begin{tabular}{|l|l|c|}
\hline \multicolumn{1}{|c|}{ Elements } & \multicolumn{1}{|c|}{ Describe and Function } \\
\hline Actor & $\begin{array}{l}\text { Behavioral classifier that specifies a role played by } \\
\text { an external entity that interacts with the subject (e.g. } \\
\text { exchange, add). }\end{array}$ \\
\hline Use Case & $\begin{array}{l}\text { Describe the features provided by the system and de- } \\
\text { fine its requirements. It is in the form of an ellipse } \\
\text { containing the name of the use case }\end{array}$ \\
\hline Association & $\begin{array}{l}\text { The communication path between an actor and a use } \\
\text { case that is part of the system. }\end{array}$ \\
\hline Include & $\begin{array}{l}\text { The insertion of additional behavior into a base use } \\
\text { case that explicitly describes the insertion. }\end{array}$ \\
\hline
\end{tabular}




\subsection{Class diagram}

The various spots of the administrator can be presented according to a diagram called "Class Diagram" Fig 2. This diagram shows that the administrator plays a role very important for the management of the platform while assuring [20-21]:

- The management of the accounts of users as well as the data of users; he can accept as he can refuse the registration of a learner by an e-mail of confirmation.

- The management of the reservations: after the registration the learner has to make a reservation to cross a precise manipulation, thus the role of the administrator is to manage this reservation according to the priority of access by taking into account the spare time of the manipulation proposed by the system.

- The management of the queue: a faith the confirmation of reservation is made, the demand of the learner passes in the queue to cross the chosen manipulation.

- The management of documents and theoretical publications of every manipulation.

- The management of the security of the platform.

- The maintenance

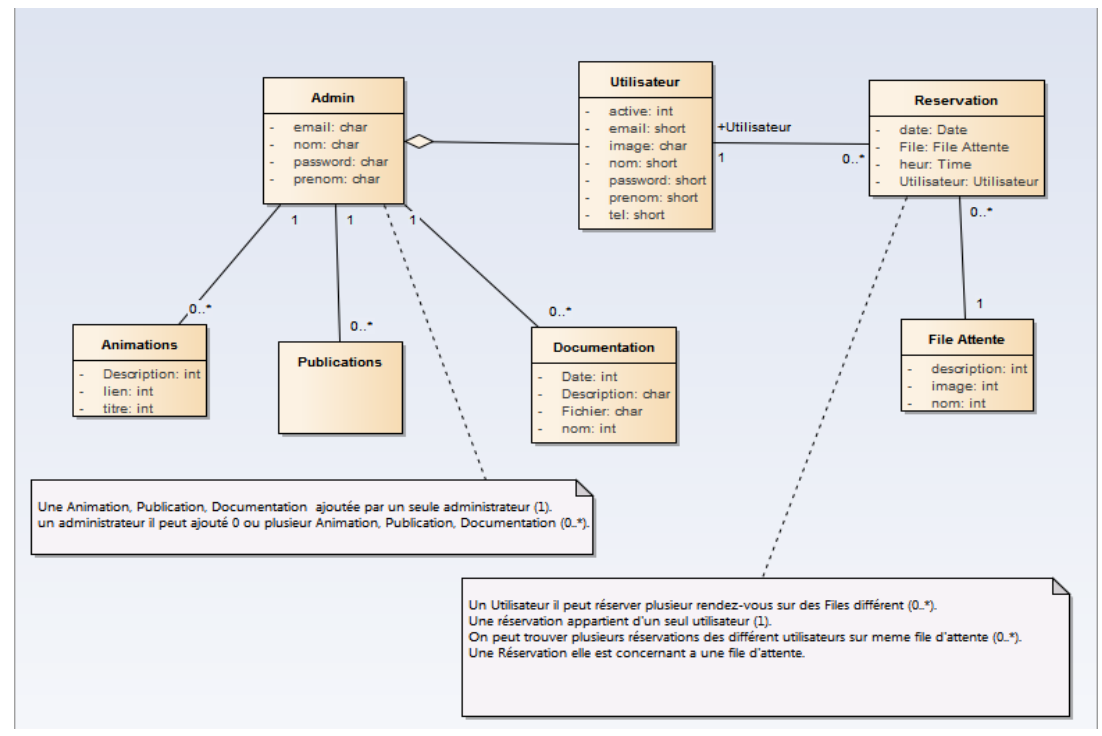

Fig. 2. Class Diagram

\subsection{Sequence diagram}

The registration in our platform requires to fill the online registration form which contains some personal information (Name, Surname, Password, Email, Telephone, Establishment,), and wait for the registration validation by the 'administrator. .

After validation of the registration by the administrator, the data will be recorded on the database, and the registration applicant receives an email confirmation of his registration on our platform. 


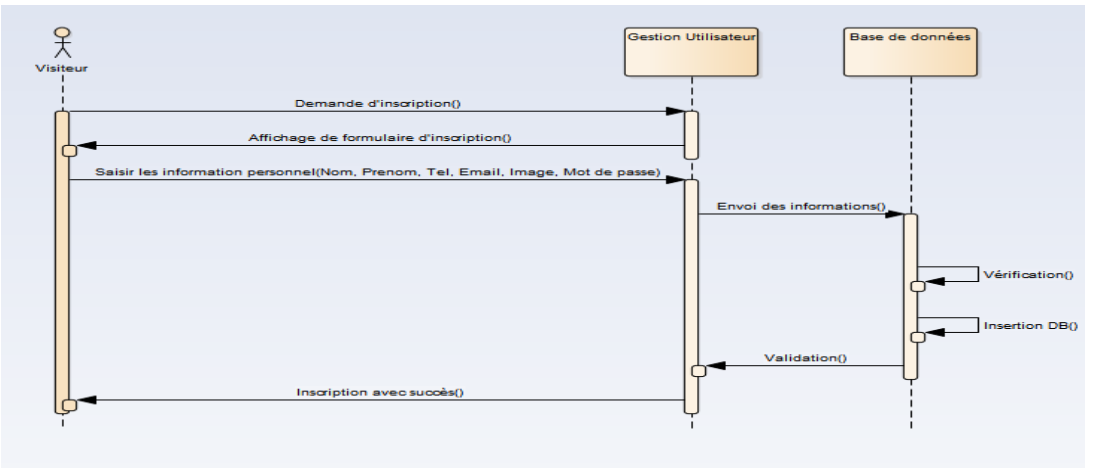

Fig. 3. Sequence Diagram (Inscription)

The user can easily access our platform by entering his username and password. If the user forgets his username, he can retrieve it easily thanks to our password recovery system integrated into our platform.

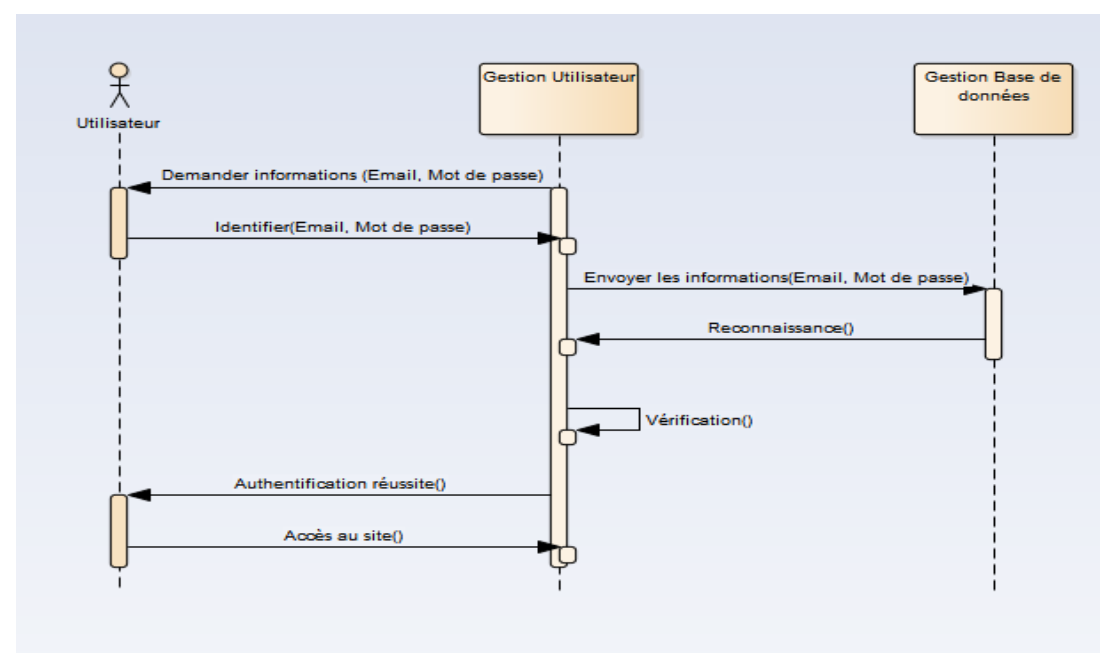

Fig. 4. Sequence Diagram (authentification)

These diagrams will be programmed based on the programming languages. This allowed us to implement our platform.

\section{Implementation of the Platform and the Queue}

\subsection{Elab FSBM Platform}

Our ELAB FSBM platform was hosted under the web address http:/www.elabfsbm.com (Fig 5). This platform contains the documentation (theoretical study and 
practical guide) of each experiment and their simulated animations that allow the user a clear idea of the experiment before moving on to the experimental part, as well as to protect the laboratory instruments when using them.

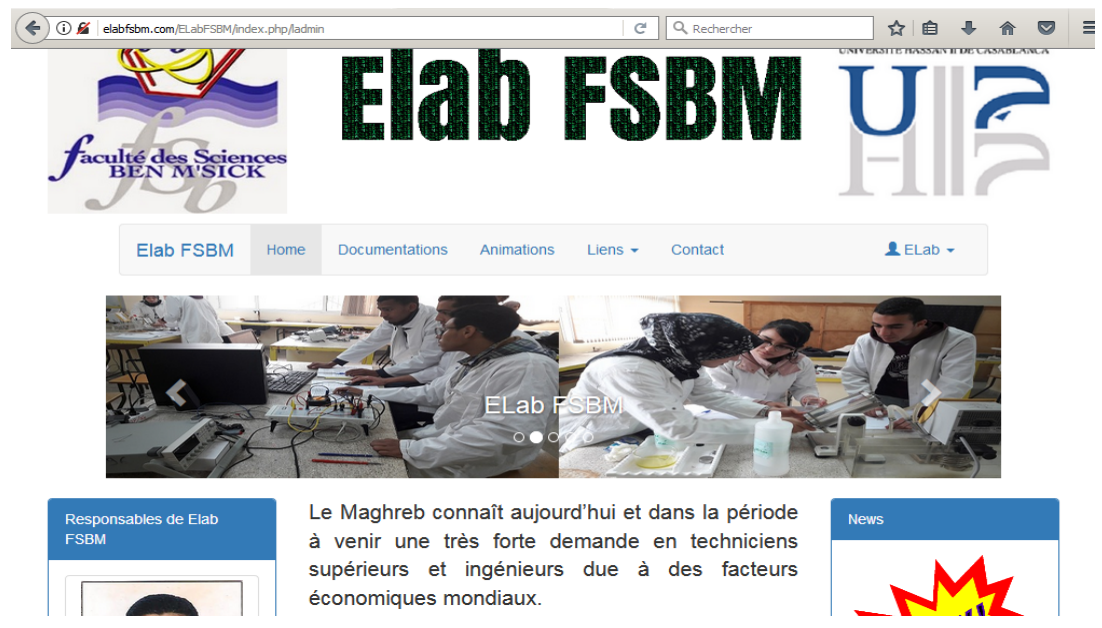

Fig. 5. ELAB FSBM Platform

\subsection{Inscription and Reservation (Calendar Booking)}

When the learner asks for a registration in our platform, a form of the personal data will be shown.

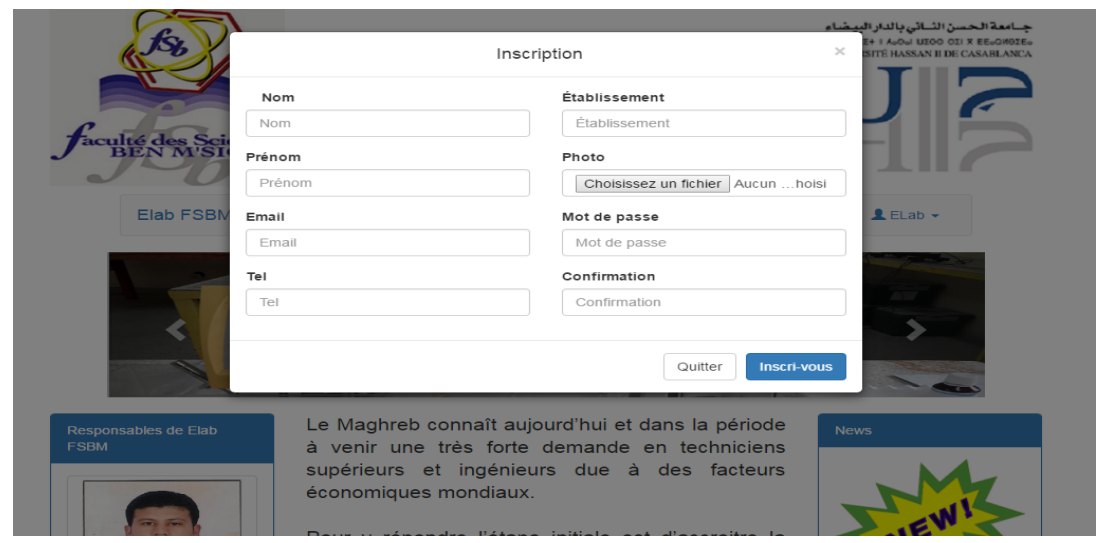

Fig. 6. Registration Form

Figure 7, shows the connection case of a user, just dial the name and password for the connection. 


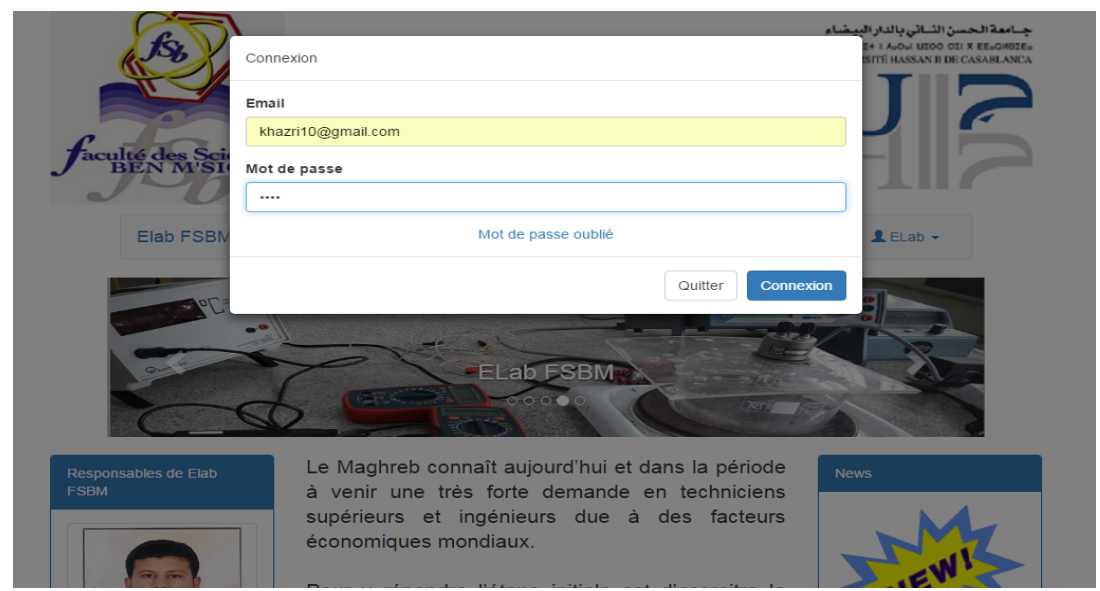

Fig. 7. Connection to the laboratory

This form of access request allows users to make a reservation offering guaranteed access to an experience (or group of experiences) at a given time. Resource allocations occur as follows [22-23-24]:

- The user requests a registration in the platform, he completes a registration form, this form sends to the administrator who will accept and authorize this request (Fig 7).

- The user attempts to connect to the ELAB FSBM server, is authenticated (Fig 8), and then receives a list of platforms (and platform pools) for which he has the necessary permissions.

- The user selects an experiment (or group of experiments), then sees the current status of the installation and the possibility of making a reservation or queuing for access (Fig. 8).

- If the user selects "Access", the booking page appears with the available slots.

- Once the slot is selected, the reservation will be created. A confirmation message will appear and an e-mail will be sent to the user with the details of the booking. The platform reservation page displays the reserved locations (in gray) for all future accesses. The system can be configured to limit the number of active reservations that can be made by a user and prevent the user from making multiple simultaneous reservations on multiple types of platforms.

- When a user is logged in and a reservation is pending (within a configurable time), their main screen changes to provide a countdown at the beginning of their session. As soon as the time of the reservation arrives, the user is assigned to the device, the device page appears and the test session will be active.

\subsection{Access to the laboratory (Priority Queuing)}

During the connection, an interface (Figure 8) will be displayed gathering all the experiences we have developed so far in our laboratory ELAB FSBM at the Faculty of Sciences of Ben M'Sik Casablanca. The user will have the right either to access any 
manipulation by clicking on "access" or just to see a small description of the manipulation by clicking on "description"[25].

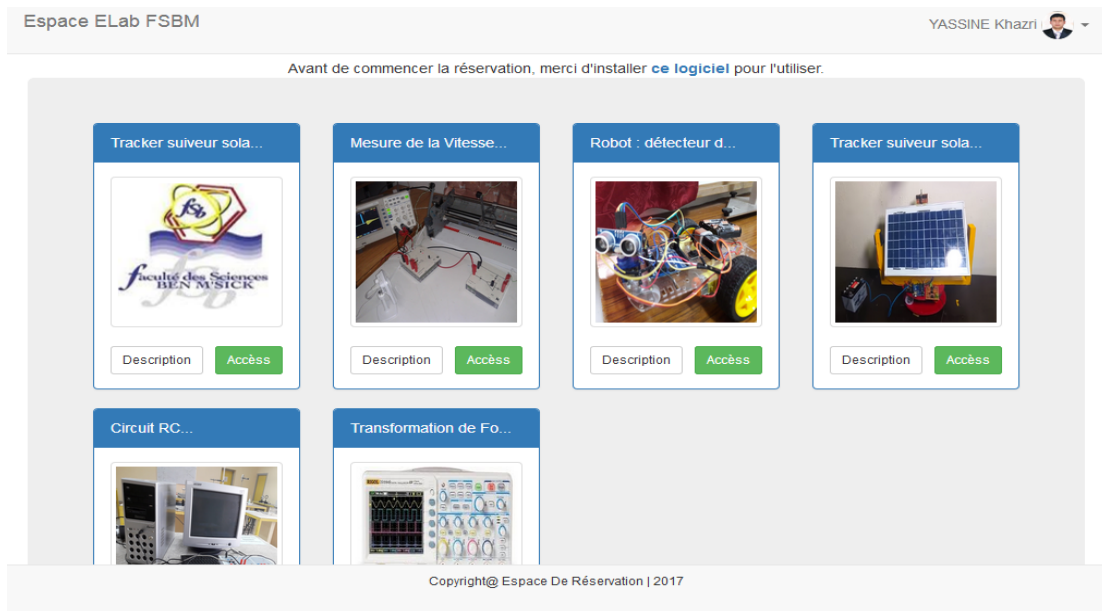

Fig. 8. Access to the laboratory

After choosing an experiment, the system will ask the learner to specify an appointment for the handling, ie to make the reservation of the date and time (Fig 9). Each booked appointment will be illegal for another learner, which means that the manipulation will be available for a single user.
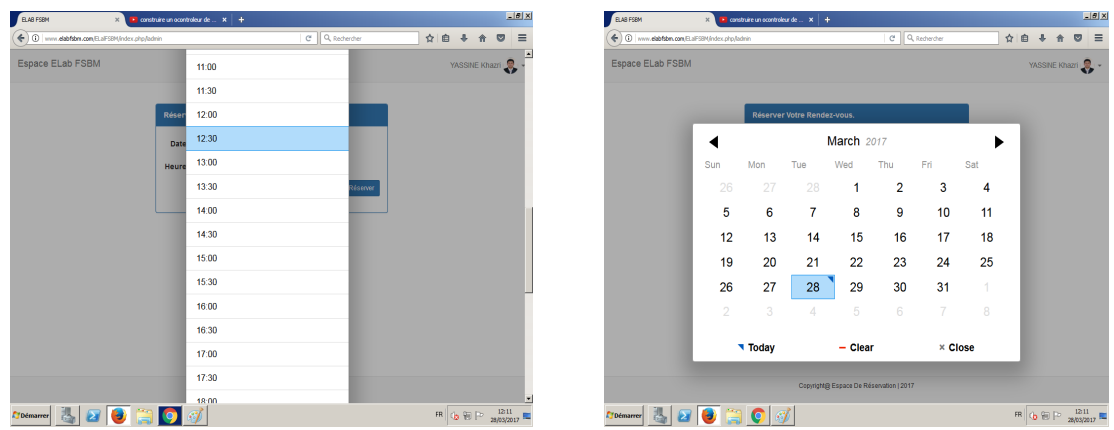

Fig. 9. Reservation of date and time

Queuing supports "on-demand" requests from users, providing "fastest available", access to an experiment. The queuing process is as follows:

- The user selects the "Access" option (Fig. 8). The request is placed in the queue, with the associated information indicating which platform they requested access to, the default usage time specified for their user class, and any other relevant parameters. The user receives information about his current position in the queue. 
- When a platform is available, ELAB FSBM searches the queue for the first request among those with the highest priority and that meets the following criteria:

- The request relates to the experience is available;

- The request can be completed before the next reservation for this resource (that is, the next session reserved for this resource is not earlier than the current time plus the default usage time of that resource).

Note that this allocation strategy ensures that a platform will only be allocated to a queue user if it can be guaranteed that it will have the full amount of time to which it is entitled, choose to use it.

- Once a user is assigned to a platform, the platform page appears and the test session starts, including a timer with system-defined session time (Fig 9).

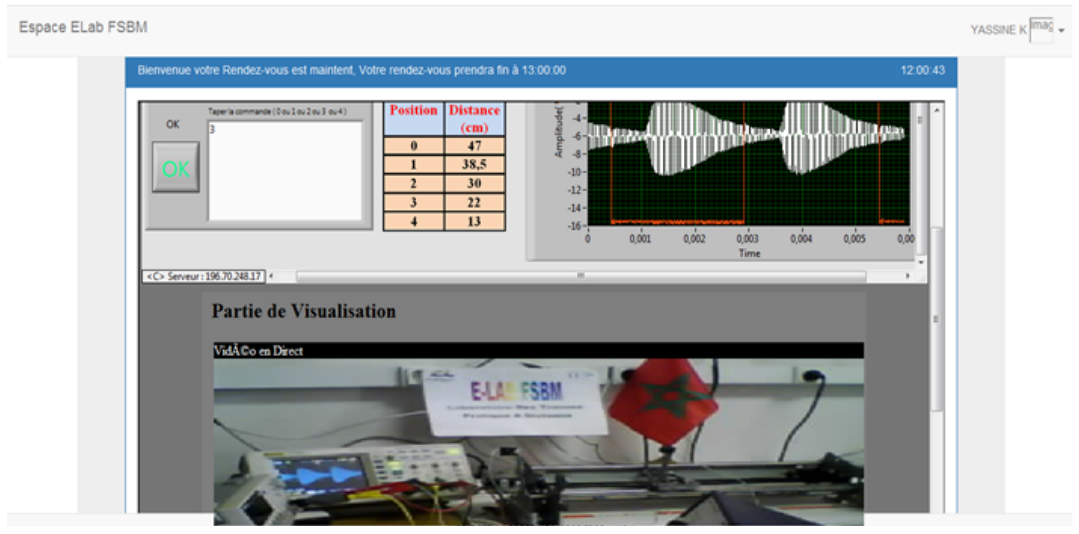

Fig. 10.Interface of experiment

In both types of scheduling, once the platform is assigned, the platform session will begin immediately. If the user is currently logged in, they will be redirected to the appropriate rig access page. If the user is not logged in after 10 minutes, the session will expire. The latter will also be closed when the user logs off or remains idle for a configurable duration, or if the allowed session time is completed and no further extension is allowed (a session can usually be extended by a finite number of times).

If no queued user wants to use the platform or no reservation is pending for this platform.

\section{Conclusion}

Laboratory experimentation plays an essential role in engineering and scientific education. Virtual and remote labs reduce the costs associated with conventional handson labs due to their required equipment, space, and maintenance staff [26-27]. 
Furthermore, they provide additional benefits such as supporting distance learning, improving lab accessibility to handicapped people, and increasing safety for dangerous experimentation [28].

In this article, we have described the implementation of the ELAB FSBM platform for learners / teachers in a distance learning activity. This environment allows teachers to supervise learners and learners to consult and carry out practical work in an individual or collaborative remote way. As well as, we have proposed an informatics solution for the management of queue of users (learners / teachers) in our platform ELAB FSBM.

First of all, we started with the UML design of our platform, for that we built the use case diagram which represents the main elements of our platform. After we presented the class diagram and the sequence diagram of the platform. As a result, we have chronologically shown the steps to follow from inscription to manipulation.

\section{$5 \quad$ References}

[1] Karsenti, Thierry et Charlin, Bernard. Analyse des impacts des technologies de l'information et de la communication sur l'enseignement et la pratique de la médecine. Pédagogie Médicale, 2010, vol. 11, no 2, p. 127-141. https://doi.org/10.1051/pmed/2010012

[2] Hussain, Aftab M. et Hussain, Muhammad M. CMOS-technology-enabled flexible and stretchable electronics for internet of everything applications. Advanced Materials, 2016, vol. 28, no 22, p. 4219-4249. https://doi.org/10.1002/adma.201504236

[3] Lee, In et LEE, Kyoochun. The Internet of Things (IoT): Applications, investments, and challenges for enterprises. Business Horizons, 2015, vol. 58, no 4, p. 431-440. https://doi.org/10.1016/j.bushor.2015.03.008

[4] Misra, Gourav, Kumar, Vivek, Agarwal, Arun, et al. Internet of things (iot)-a technological analysis and survey on vision, concepts, challenges, innovation directions, technologies, and applications (an upcoming or future generation computer communication system technology). American Journal of Electrical and Electronic Engineering, 2016, vol. 4, no 1, p. 23 32.

[5] KIM, Taekyun, Sotirova, Evdokia, Shannon, Anthony, et al.Interval valued intuitionistic fuzzy evaluations for analysis of a student's knowledge in university e-learning courses. International Journal of Fuzzy Logic and Intelligent Systems, 2018, vol. 18, no 3, p. 190-195. https://doi.org/10.5391/ijfis.2018.18.3.190

[6] Poliakov, Mykhailo, Henke, Karsten, et Wuttke, Heinz-Dietrich. The augmented functionality of the physical models of objects of study for remote laboratories. In : Online engineering \& Internet of Things. Springer, Cham, 2018. p. 151-159. https://doi.org/10. 1007/978-3-319-64352-6 15

[7] Machado, Guido Soprano, Silva, Yuri Motta Lopes Rodrigues, et De Lucena, Vicente Ferreira. A Tool for the Automatic Selection of Mechatronics Remote Laboratories based on their Actual Effective Costs. In: 2018 IEEE Frontiers in Education Conference (FIE). IEEE, 2018. p. 1-5. https://doi.org/10.1109/fie.2018.8658732

[8] Parkhomenko, Anzhelika, Parkhomenko, Andriy, Tabunshchyk, Galyna, et al. The remote labs as an effective tool of inclusive engineering education. In: 2018 XIV-th International Conference on Perspective Technologies and Methods in MEMS Design (MEMSTECH). IEEE, 2018. p. 209-214. https://doi.org/10.1109/memstech.2018.8365735 
[9] STROEVA, Olesya A., Zviagintceva, Yuliia, Tokmakova, Elena, et al. Application of remote technologies in education. International Journal of Educational Management, 2019, vol. 33, no 3, p. 503-510. https://doi.org/10.1108/ijem-08-2018-0251

[10] Wuttke, Heinz-Dietrich, Parkhomenko, Anzhelika, Tulenkov, Artem, et al. The Remote Experimentation as the Practical-Oriented Basis of Inclusive Engineering Education. International Journal of Online Engineering, 2019, vol. 15, no 5. https://doi.org/ 10.3991/ijoe.v15i05.9752

[11] Admiraal, Wilfried, POST, Lysanne, Guo, Pengyue, et al.Students as Future Workers: Cross-border Multidisciplinary Learning Labs in Higher Education. International Journal of Technology in Education and Science, 2019, vol. 3, no 2, p. 85-94.

[12] Lowe, David. Integrating reservations and queuing in remote laboratory scheduling. IEEE Transactions on Learning Technologies, 2013, vol. 6, no 1, p. 73-84. https://doi. org/10.1109/tlt.2013.5

[13] Hegarty, Elizabeth H. Levels of scientific enquiry in university science laboratory classes: Implications for curriculum deliberations. Research in Science Education, 1978, vol. 8, no 1, p. 45-57. https://doi.org/10.1007/bf02558676

[14] Hofstein, Avi et Lunetta, Vincent N. The role of the laboratory in science teaching: Neglected aspects of research. Review of educational research, 1982, vol. 52, no 2, p. 201-217. https://doi.org/10.3102/00346543052002201

[15] Lowe, D. et Orou, N. Interdependence of booking and queuing in remote laboratory scheduling. In: 2012 9th International Conference on Remote Engineering and Virtual Instrumentation (REV). IEEE, 2012. p. 1-6. https://doi.org/10.1109/rev.2012.6293100

[16] Tutorials point, "UML overview," [Online] http://www.umldiagrams.org/use-casediagrams.html, December 2014.

[17] MediaGroup1 LLC, "Unified modeling language planning with diagrams," [Online] http://www.dreamincode.net/forums/topic/49062-unifiedmodeling-language/, December 2014.

[18] Mohmed Salah, Razwan, ALVES, Gustavo R., Guerreiro, Pedro, et al. Using UML models to describe the VISIR system. International Journal of Online Engineering, 2016, vol. 12, no 06, p. 34. https://doi.org/10.3991/ijoe.v12i06.5707

[19] Farag, Wael. An innovative remote-lab framework for educational experimentation. International Journal of Online Engineering (iJOE), 2017, vol. 13, no 02, p. 68-86. https://doi.org/10.3991/ijoe.v13i02.6609

[20] Spilakova, Petra et Schauer, Frantisek. Remote laboratory management system remlabnet and its booking system. In: 2015 Forth International Conference on e-Technologies and Networks for Development (ICeND). IEEE, 2015. p. 1-5. https://doi.org/ 10.1109/icend.2015.7328544

[21] AK, Ayça, Topuz, Vedat, Altikardeş, Aysun, et al. Development of a Remote Laboratory Infrastructure and LMS for Mechatronics Distance Education. EURASIA Journal of Mathematics, Science and Technology Education, 2018, vol. 14, no 6, p. 2493-2508. https://doi.org/10.29333/ejmste/89947

[22] Jović, Nikola et Matijević, Milan. Design of WEB Laboratory for Programming and Use of an FPGA Device. In: Online Engineering \& Internet of Things. Springer, Cham, 2018. p. 809-821. https://doi.org/10.1007/978-3-319-64352-6 75

[23] SLAPP III, Robert J. Virtual classroom management delivery system and method. U.S. Patent Application No 10/187,192, 22 janv. 2019.

[24] Mcgann, Conor, Grigoropol, Ioana, Orshansky, Masha, et al. System and method for extracting domain model for dynamic dialog control. U.S. Patent Application No 15/986,787, 22 nov. 2018. 
[25] Khazri, Yassine, Al Sabri, A., Sabir, B., et al. Development and Management of a Remote Laboratory in Physics for Engineering Education (E-LAB FSBM). In: Proceedings of the 2nd international Conference on Big Data, Cloud and Applications. ACM, 2017. p. 103. https://doi.org/10.1145/3090354.3090460

[26] Heradio, Ruben, De La Torre, Luis, Galan, Daniel, et al. Virtual and remote labs in education: A bibliometric analysis. Computers \& Education, 2016, vol. 98, p. 14-38. https://doi.org/10.1016/j.compedu.2016.03.010

[27] Potkonjak, Veljko, Gardner, Michael, Callaghan, Victor, et al. Virtual laboratories for education in science, technology, and engineering: A review. Computers \& Education, 2016, vol. 95, p. 309-327. https://doi.org/10.1016/j.compedu.2016.02.002

[28] Montgomery, Douglas C. Design and analysis of experiments. John wiley \& sons, 2017.

\section{Authors}

Yassine Khazri is with Hassan II University at Casablanca city in Morocco. His mail is khazri10@gmail.com

Ahmed Fahli is with Hassan I University at Settat in Morocco.

Mohammed Moussetad is with Hassan II University at Casablanca in Morocco.

Ahmed Naddami is with Hassan I University at Settat in Morocco.

Article submitted 2019-06-24. Resubmitted 2019-07-28. Final acceptance 2019-07-29. Final version published as submitted by the authors. 